\title{
Neuromuscular exercises: A new perspective in knee osteoarthritis
}

\author{
Jyoti Sabharwal, Shabnam Joshi \\ Department of Physiotherapy, Guru Jambheshwar University of Science \&Technology, Hisar, Haryana, India
}

\begin{abstract}
Background. Knee osteoarthritis $(O A)$ is the most prevalent arthropathy across the world. It presents with swelling, pain, decreased range of motion (ROM) and instability. Patients also complain of thigh muscle weakness and lower limb weakness resulting in poor joint shielding and joint overload. Owing to these presenting features patients are prone to increased risk of morbidity and are forced to live with functional impairment. Exercises are one of the vital intervention programme used in knee OA. Exercises lead to improvement in physical function, strengthening of the muscles and reduction in pain. Neuromuscular exercises have effects on functional performance, biomechanics and activation pattern of surrounding musculatures of the patient. Therefore, neuromuscular exercises may prove to be beneficial in enhancing the efficacy of exercise training programmes in such patients due to functional instability and disturbed neuromuscular function.

Purpose. This article intends to review the effect and role of neuromuscular exercises in the management of knee osteoarthritis.

Method. Comprehensive computerized search was performed on Google Scholar, Pubmed and Cochrane.

Conclusion. By evaluating various articles on neuromuscular exercises in knee osteoarthritis the present review suggests that neuromuscular exercises are helpful in the treatment of knee osteoarthritis.
\end{abstract}

Keywords: knee osteoarthritis, neuromuscular exercises, knee joint, joint load

\section{INTRODUCTION}

Knee osteoarthritis (OA) is a prevalent arthritic condition which leads to reduced physical function and pain leading to poor quality of life (QOL) [1]. It affects about one third of population, and this may progress to aggravated stage of condition which is often an indication for knee joint replacement [2]. The incidence rates for replacement of knee in western countries are increasing every year [3]. Knee OA patients present with instability, pain, swelling, and decreased range of motion. These presenting features cause impairment in functional activities which increases the morbidity and fatality in affected person [4,5]. Knee joint consist of two articulating joints which are tibiofemoral joint and patellofemoral joint. The surface of knee joint is lined by hyaline cartilage which is enclosed within a single joint cavity. The synovium secretes excess amount of synovial fluid, which causes capsular swelling because of invasion by inflammatory cells [6]. The capsular swelling and joint disuse inhibits muscle activation and may cause weakness and atrophy of muscles [7]. The etio-pathogenesis of knee $\mathrm{OA}$ is depicted in figure 1.Numerous factors such as joint injuries, abnormal lower limb biomechanics and neuromuscular control, poor flexibility and quadriceps deficit may lead to development of knee OA shown in figure 2. Quadriceps muscle acts as shock absorber during joint loading. The thigh muscle weakness leads to reduced joint protection resulting in joint overloading [6]. 


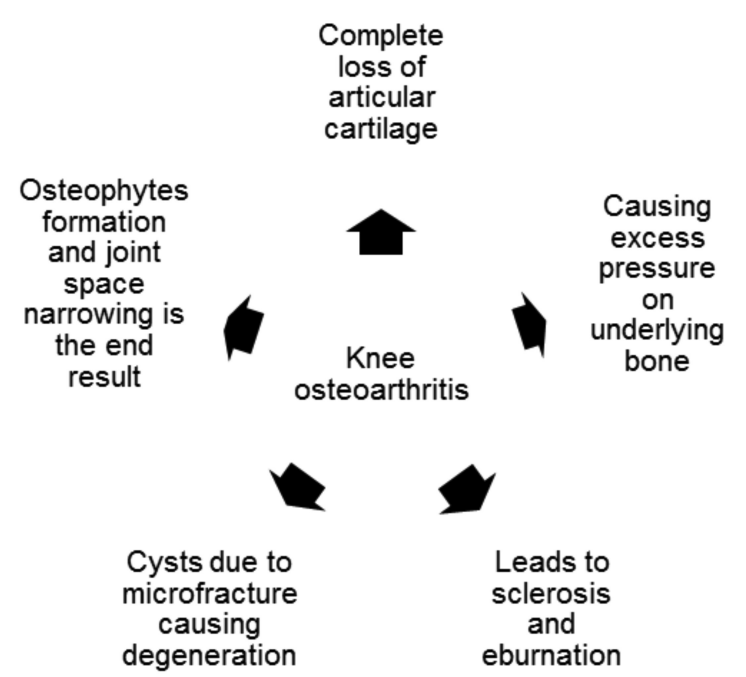

FIGURE 1. Etiopathogenesis of knee osteoarthritis

\section{SENSORI-MOTOR DEFICIENCY IN KNEE OSTEOARTHRITIS}

Sensori-motor deficits are present at various levels of the sensori-motor system which may include the sensory input through integration and processing of information of motor output to do movements and to maintain postural control. These sensori-motor deficits play important role in the development and progression of degenerative disease around knee joint. Rice and McNair describe the mechanism for the neural inhibition of the quadriceps muscle in knee osteoarthritis [8]. Pain, swelling, inflammation, joint laxity and damage to sensory receptors in the joint cause the neural inhibition. And these factors inhibit the muscle to be fully activated by altered excitability of spinal and supraspinal pathways [8]. This inability of muscle to freely activate is a major contributing element for the weakness of quadriceps muscle and may enhance the chances of knee osteoarthritis. Neuromuscular exercise (NEMEX) programs include the various sensori-motor function and functional stability for improving function and to reduce the symptoms.

\section{TREATMENT METHODS}

Various treatment options are available to treat symptoms and upgrade quality of life in patients. NEMEX alleviates pain, improves joint function, knee joint biomechanics, and muscle-activation patterns of adjoining knee muscles in patients with knee osteoarthritis. Furthermore, NEMEX has been shown to improve quality of articular cartilage in patients who had meniscectomies and are at high risk of knee osteoarthritis [9]. This suggests that NEMEX may have important role in knee OA management and benefit the patients who are at risk for or with early-stage knee OA. Clinical guidelines recommend nondrug treatments including patient education, various exercises (i.e., aerobic conditioning, strength training, and neuromuscular exercise) and weight loss as the first line of treatment [9-11]. Exercises leads to strengthening of the muscles, reduction of pain and improvement in physical function. Thus, exercises are a vital part of physiotherapy intervention in the management of knee osteoarthritis [11]. Stretching exercises along with strengthening exercises are widely used to increase the range of motion and are often advised in recovery phase as a routine warm-up to prepare the muscles for the other exercises programmes [12,13]. Aerobic exercise and strengthening exercises play an important role in terms of pain reduction as well as improvement in physical function level [14-17]. Earlier work involving the use of exercises has focused on investigating the efficacy of various types of exercises on functional aspects. However, it is pertinent to mention that knee osteoarthritis patients suffer defective neuromuscular function and functional instability impairments $[18,19]$. Neuromuscular exercises are those types of exercises which particularly target neuromuscular impairments in knee osteoarthritis. So it is important to understand their role in the rehabilitation and management of knee osteoarthritis. Therefore, NEMEX may be used to enhance the efficacy of training session [20]. The major goal of the NEMEX is to improve the functional joint stability \& sensori-motor control. NEMEX is different from other

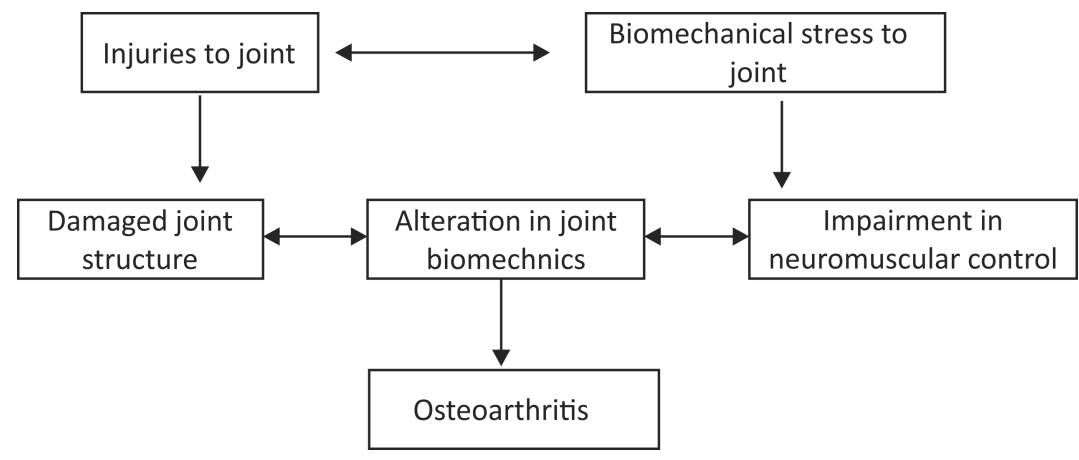

FIGURE 2. Interaction between various contributing factors for osteoarthritis 
standard exercise programs used for osteoarthritis, which are mainly aimed at improving cardiovascular output or muscle power [21-23].This review attempts to understand and discuss the role of NEMEX in knee osteoarthritis.

\section{NEUROMUSCULAR TRAINING}

\section{An intervention in knee OA - neuromuscular exercise (NEMEX)}

NEMEX consists of various exercises for improving functional alignment, muscle activation, balance and joint stability. Alike standard strength training, neuromuscular exercise is different in terms of quality of movement. Neuromuscular exercises also affect biomechanics of knee functional performance as well as knee muscles activation patterns [24, 25]. Previous studies state that NEMEX has proven potential to decrease knee-joint loading and also improves the quality of cartilage grid in people with mild disease [26-28]. NEMEX can be used in rehabilitation of anterior cruciate ligament injury and moderate to severe knee OA [29-34].

\section{Neuromuscular exercise program}

Each exercise session consists of three phases which are: Warming up phase, NEMEX and cooling down phase. Warm up phase consist of general ergo meter cycling, treadmill walking, or stepping exercise (10 minutes) [35]. NEMEX consist of various exercises with the described keystones: functional presentations, posture control, strength of lower extremity, balance, and functional stabilization of trunk and knee. All exercises performed in closed kinetic chain. Cooling down phase includes gait retraining, backward walking (retro walking) focus- ing on proper positioning and stretching exercises for the lower extremities for ten minutes [36,37].

\section{Principles}

NEMEX training is primarily based on two principles: biomechanical principle and neuromuscular principle that particularly aim to improve sensori-motor control and dynamic functional stability [23]. Key features of neuromuscular principles are depicted in Table 1.

\section{Role of neuromuscular training in sports}

Previous studies stated the various risk factors including neuromuscular as well as biomechanical factors for anterior cruciate ligament injury $[38,39]$. The ACL injuries are commonly associated with deficient neuromuscular control which leads to alteration in biomechanics of lower extremity further which increase the knee valgus, foot pronation angles and decrease angle of hip, knee flexion and hip abduction. Neuromuscular training has been found in reducing the risk of cruciate ligament injury by ameliorating the biomechanical deficits in female athletes if neuromuscular training is used before puberty onset.

\section{Role of NEMEX in joint loading and muscle activation pattern in patients with knee osteoarthritis}

Various pilot studies proves knee-joint load reduction leads to improvement in cartilage grid quality in those especially who are with mild osteoarthritic changes [23,40,41]. Neuromuscular exercises are widely used in physiotherapy practice for recovery in patients with OA [42-44]. Only few stud-

TABLE 1. Principles of neuromuscular exercises

\begin{tabular}{|l|l|}
\hline Neuromuscular principles & Biomechanical principles \\
\hline $\begin{array}{l}\text { 1. The active movements are performed in synergy. Sensory-motor } \\
\text { synergy exist around the anatomical structure of knee which } \\
\text { includes the ligaments, muscles, bones and capsule. The synergism } \\
\text { is required to maintain stability in the joint physical activities. } \\
\text { Muscle strengthening exercises improves the knee joint stability. }\end{array}$ & $\begin{array}{l}\text { 1. Biomechanical principles are the basis for neuromuscular } \\
\text { kinetic chain for training the antigravity muscles of the affected } \\
\text { extremity. }\end{array}$ \\
\hline $\begin{array}{l}\text { 2. The active movement starts at the sound extremity with normal } \\
\text { movement and thereafter, a bilateral transfer effect of motor } \\
\text { learning is achieved at affected extremity. }\end{array}$ & $\begin{array}{l}\text { 2. To attain equilibrium of weight bearing extremity in activities } \\
\text { of daily living as well as during strenuous activities. }\end{array}$ \\
\hline $\begin{array}{l}\text { 3. Exercises are performed in a closed kinetic chain at varying } \\
\text { positions for even distribution of articulating pressure via the } \\
\text { muscle co-activation. Muscle co-activation is associated with } \\
\text { different types of joint loading. By evaluating the co-activation } \\
\text { pattern of muscle it become easy to develop therapeutic strategies } \\
\text { which will be beneficial in functional improvement. }\end{array}$ & $\begin{array}{l}\text { 3. By achieving equilibrium postural control is attained without } \\
\text { any unted compensatory movements. }\end{array}$ \\
\hline $\begin{array}{l}\text { 4. The quality of performance should be focused in each exercises } \\
\text { with an appropriate position of hip, knee and foot properly aligned } \\
\text { i.e. postural orientation is emphasized. And the progression } \\
\text { depends upon neuromuscular function patient. }\end{array}$ & $\begin{array}{l}\text { 4. The biomechanical principles model focuses on the postural } \\
\text { function and reaction of the anti gravity muscles in the affected } \\
\text { extremity thereafter initiating the voluntary movement of the } \\
\text { sound extremity. }\end{array}$ \\
\hline
\end{tabular}


ies found the effect of neuromuscular exercises on knee joint loads $[40,42,45]$. A pilot study conducted which includes thirteen patients of mild knee OA found fourteen percent of reduction in external peak knee adduction moment after 8 weeks of NEMEX $[40,46]$. Neuromuscular exercises targets on the ability of movement of lower extremities and activation patterns of movement which can be helpful in improving dynamic knee joint load [47,48]. The muscle inability is considered a major determinant for quadriceps weakness and development of osteoarthritis. The goal of NEMEX is to improve the appropriate activation of muscle to obtain functional joint stabilization, joint load reduction and thereby amends the patient's function and decrease the symptoms.

\section{NEMEX as an injury prophylaxis}

Anterior cruciate ligament injuries occur due to loss of coordination and normal protective muscle support [49]. Neuromuscular training increase active knee joint stabilization and decrease the chance of knee injury, including anterior cruciate ligament injuries, in an athletic population. Caraffa et al. found that neuromuscular training significantly decreased the ACL injuries in high level male soccer players [50]. NEMEX program increase muscle power and strength, hamstrings to quadriceps peak torque ratios. Hewett et al. reported that untrained female players had significantly more chances of knee joint injury than the trained players [51].

\section{Role of NEMEX in pain and function and balance in patients with knee osteoarthritis}

Bennell et al. conducted a study to compare the neuromuscular exercise with quadriceps strengthening in patients with knee osteoarthritis and found improvements in terms of pain, physical function and knee adduction moment. Another study by Bennell et al. found that people with varus thrust had a larger reduction in pain with neuromuscular exercises than with quadriceps strengthening exercises [17,20,22,28,43]. Neuromuscular training method mainly aimed to improve the sensori-motor control and to attain functional stability. The neuromuscular training programs may be more effective in terms of improvements in balance, coordination and motion quality, function, activation pattern [52,53]. The effects of neuromuscular training have been studied in patients with acute ACL injuries and found that muscle strength and functional performance improved in neuromuscular training group than conventional group.

\section{CONCLUSIONS}

Joint loading plays an important role in development and further progression of the disease. Therapies directing towards mechanical load, sensorimotor control, are useful in treatment of knee osteoarthritis. The neuromuscular training focuses on the functional instabilities, muscle activation pattern and functional joint stabilization of knee. Neuromuscular exercises can be helpful in decreasing the pain, improving the function, activation pattern and decrease the knee joint loading and sensorimotor deficiency that is the potential contributing factor in both development and progression of knee osteoarthritis.

\section{Acknowledgement}

The authors would like to acknowledge Dr. Rekha Chaturvedi for her support in exploring the role of neuromuscular exercises in knee osteoarthritis.

Conflict of interest: none declared Financial support: none declared

\section{REFERENCES}

1. Bitton R. The economic burden of osteoarthritis. The American Journal of Managed Care. 2009 Sep 1;15(8):230-5.

2. Lachance L, Sowers MF, Jamadar D, Hochberg M. The natural history of emergent osteoarthritis of the knee in women. Osteoarthritis and Cartilage. 2002 Nov 1;10(11):849-54.

3. Bentley G, editor. European Instructional Lectures: Volume 10, 2010; 11th EFORT Congress, Madrid, Spain. Springer Science \& Business Media; 2011 Jan 21.

4. Maurer BT, Stern AG, Kinossian B, Cook KD, Schumacher Jr HR. Osteoarthritis of the knee: isokinetic quadriceps exercise versus an educational intervention. Archives of physical medicine and rehabilitation. 1999 Oct 1;80(10):1293-9.

5. Fidelix TS, Soares BG, Trevisani VF. Diacerein for osteoarthritis. Cochrane Database Syst Rev. 2006 Jan 25;(1):CD005117.

6. Hurley MV. The role of muscle weakness in the pathogenesis of osteoarthritis. Rheumatic Disease Clinics of North America. 1999 May 1;25(2):283-98.
7. Felson DT. Developments in the clinical understanding of osteoarthritis. Arthritis Research \& Therapy. 2009 Feb;11(1):1-1.

8. Risberg MA, Holm I, Myklebust G, Engebretsen L. Neuromuscular training versus strength training during first 6 months after anterior cruciate ligament reconstruction: a randomized clinical trial. Physical Therapy. 2007 Jun 1;87(6):737-50.

9. Roos EM, Dahlberg L. Positive effects of moderate exercise on glycosaminoglycan content in knee cartilage: a four-month, randomized, controlled trial in patients at risk of osteoarthritis. Arthritis \& Rheumatism. 2005 Nov;52(11):3507-14.

10. Jordan KM, Arden NK, Doherty M, Bannwarth B, Bijlsma JW, et al. EULAR Recommendations 2003: an evidence based approach to the management of knee osteoarthritis: Report of a Task Force of the Standing Committee for International Clinical Studies Including Therapeutic Trials (ESCISIT). Annals of the rheumatic diseases. 2003 Dec 1;62(12):1145-55. 
11. Zhang W, Moskowitz RW, Nuki G, Abramson S, et al. OARSI recommendations for the management of hip and knee osteoarthritis, Part II: OARSI evidence-based, expert consensus guidelines. Osteoarthritis and Cartilage. 2008 Feb 1;16(2):137-62.

12. Messier SP, Loeser RF, Miller GD, Morgan TM, Rejeski WJ, Sevick MA, Ettinger Jr WH, Pahor M, Williamson JD. Exercise and dietary weight loss in overweight and obese older adults with knee osteoarthritis: the Arthritis, Diet, and Activity Promotion Trial. Arthritis \& Rheumatism. 2004 May;50(5):1501-10.

13. Reid DA, McNair PJ. Effects of an acute hamstring stretch in people with and without osteoarthritis of the knee. Physiotherapy. $2010 \mathrm{Mar}$ 1;96(1):14-21.

14. Halbertsma JP, Mulder I, Göeken LN, Eisma WH. Repeated passive stretching: acute effect on the passive muscle moment and extensibility of short hamstrings. Archives of physical medicine and rehabilitation. $1999 \mathrm{Apr}$ 1;80(4):407-14.

15. Zhang W, Moskowitz RW, Nuki G, Abramson S, Altman RD, et al. OARSI recommendations for the management of hip and knee osteoarthritis, part I: critical appraisal of existing treatment guidelines and systematic review of current research evidence. Osteoarthritis and Cartilage. 2007 Sep 1;15(9):981-1000.

16. Fransen M, McConnell S, Harmer AR, Van der Esch M, Simic M, Bennell KL. Exercise for osteoarthritis of the knee: a Cochrane systematic review. Br J Sports Med. 2015 Dec;49(24):1554-7.

17. Bennell K, Hinman R. Exercise as a treatment for osteoarthritis. Current opinion in rheumatology. 2005 Sep 1;17(5):634-40.

18. Hernández-Molina G, Reichenbach S, Zhang B, Lavalley M, Felson DT. Effect of therapeutic exercise for hip osteoarthritis pain: Results of a meta-analysis. Arthritis Care \& Research. 2008 Sep 15;59(9):1221-8.

19. Fitzgerald GK, Piva SR, Irrgang JJ. Reports of joint instability in knee osteoarthritis: its prevalence and relationship to physical function. Arthritis Care \& Research. 2004 Dec 15;51(6):941-6.

20. Bennell KL, Hunt MA, Wrigley TV, Lim BW, Hinman RS. Role of muscle in the genesis and management of knee osteoarthritis. Rheumatic Disease Clinics of North America. 2008 Aug 1;34(3):731-54.

21. Ageberg E, Roos EM. Neuromuscular exercise as treatment of degenerative knee disease. Exercise and sport sciences reviews. 2015 Jan 1;43(1):14-22.

22. Bennell KL, Hinman RS. A review of the clinical evidence for exercise in osteoarthritis of the hip and knee. Journal of Science and Medicine in Sport. 2011 Jan 1;14(1):4-9.

23. Ageberg $E$, Link $A$, Roos EM. Feasibility of neuromuscular training in patients with severe hip or knee OA: the individualized goal-based NEMEX-TJR training program. BMC Musculoskeletal Disorders. 2010 Dec;11(1):1-7.

24. Fitzgerald GK, Childs JD, Ridge TM, Irrgang JJ. Agility and perturbation training for a physically active individual with knee osteoarthritis. Physical Therapy. 2002 Apr 1;82(4):372-82.

25. Thorstensson CA, Henriksson M, von Porat A, Sjödahl C, Roos EM. The effect of eight weeks of exercise on knee adduction moment in early knee osteoarthritis - a pilot study. Osteoarthritis and Cartilage. 2007 Oct 1;15(10):1163-70.

26. Thorp LE, Wimmer MA, Foucher KC, Sumner DR, Shakoor N, Block JA. The biomechanical effects of focused muscle training on medial knee loads in OA of the knee: a pilot, proof of concept study. J Musculoskelet Neuronal Interact. 2010 Jun 1;10(2):166-73.

27. Roos EM, Dahlberg L. Positive effects of moderate exercise on glycosaminoglycan content in knee cartilage: a four-month, randomized, controlled trial in patients at risk of osteoarthritis. Arthritis \& Rheumatism. 2005 Nov;52(11):3507-14.

28. Bennell K, Wrigley T, Kyriakides M, Metcalf B, Roos E, et al. Comparison of neuromuscular and quadriceps strengthening exercise in people with medial knee osteoarthritis and varus malalignment: randomised controlled trial. Osteoarthritis and Cartilage. $2013 \mathrm{Apr}$ 1;21:S273-4.

29. Mandelbaum BR, Silvers HJ, Watanabe DS, Knarr JF, et al. Effectiveness of a neuromuscular and proprioceptive training program in preventing anterior cruciate ligament injuries in female athletes: 2-year follow-up. The American Journal of Sports Medicine. 2005 Jul;33(7):1003-10.
30. Henriksen M, Simonsen EB, Alkjær T, Lund H, et al. Increased joint loads during walking-a consequence of pain relief in knee osteoarthritis. The Knee. 2006 Dec 1;13(6):445-50.

31. Alentorn-Geli E, Myer GD, Silvers HJ, Samitier G, Romero D, Lázaro-Haro C, Cugat R. Prevention of non-contact anterior cruciate ligament injuries in soccer players. Part 2: a review of prevention programs aimed to modify risk factors and to reduce injury rates. Knee Surgery, Sports Traumatology, Arthroscopy. 2009 Aug 1;17(8):859-79.

32. Stensrud S, Roos EM, Risberg MA. A 12-week exercise therapy program in middle-aged patients with degenerative meniscus tears: a case series with 1-year follow-up. Journal of Orthopaedic \& Sports Physical Therapy. 2012 Nov;42(11):919-31.

33. Ericsson $Y B$, Dahlberg $L E$, Roos EM. Effects of functional exercise training on performance and muscle strength after meniscectomy: a randomized trial. Scandinavian Journal of Medicine \& Science in Sports. 2009 Apr;19(2):156-65.

34. Roos EM, Dahlberg L. Positive effects of moderate exercise on glycosaminoglycan content in knee cartilage: a four-month, randomized, controlled trial in patients at risk of osteoarthritis. Arthritis \& Rheumatism. 2005 Nov;52(11):3507-14.

35. Borg $G$, Ljunggren $G$, Ceci R. The increase of perceived exertion, aches and pain in the legs, heart rate and blood lactate during exercise on a bicycle ergometer. European Journal of Applied Physiology and Occupational Physiology. 1985 Oct;54(4):343-9.

36. Alentorn-Geli E, Myer GD, Silvers HJ, Samitier G, Romero D, Lázaro-Haro C, Cugat R. Prevention of non-contact anterior cruciate ligament injuries in soccer players. Part 2: a review of prevention programs aimed to modify risk factors and to reduce injury rates. Knee Surgery, Sports Traumatology, Arthroscopy. 2009 Aug 1;17(8):859-79.

37. Ageberg $E$, Link $A$, Roos $E M$. Feasibility of neuromuscular training in patients with severe hip or knee OA: the individualized goal-based NEMEX-TJR training program. BMC Musculoskelet Disord. 2010;11:126.

38. Hewett TE, Myer GD, Ford KR, Heidt Jr RS, et al. Biomechanical measures of neuromuscular control and valgus loading of the knee predict anterior cruciate ligament injury risk in female athletes: a prospective study. The American Journal of Sports Medicine. 2005 Apr;33(4):492-501.

39. Villadsen A, Overgaard S, Holsgaard-Larsen A, Christensen R, Roos EM. Postoperative effects of neuromuscular exercise prior to hip or knee arthroplasty: a randomised controlled trial. Annals of the Rheumatic Diseases. 2014 Jun 1;73(6):1130-7.

40. Thorp LE, Wimmer MA, Foucher KC, Sumner DR, Shakoor N, Block JA. The biomechanical effects of focused muscle training on medial knee loads in OA of the knee: a pilot, proof of concept study. J Musculoskelet Neuronal Interact. 2010 Jun 1;10(2):166-73.

41. Good Life with osteoarthritis in Denmark. Available at: www.glaid.dk.

42. Hall M, Nielsen JH, Holsgaard-Larsen A, Nielsen DB, Creaby MW, Thorlund JB. Forward lunge knee biomechanics before and after partial meniscectomy. The Knee. 2015 Dec 1;22(6):506-9.

43. Bennell KL, Kyriakides M, Metcalf B, Egerton T, et al. Neuromuscular versus quadriceps strengthening exercise in patients with medial knee osteoarthritis and varus malalignment: a randomized controlled trial. Arthritis \& Rheumatology. 2014 Apr;66(4):950-9.

44. Zhao D, Banks SA, Mitchell KH, D'Lima DD, Colwell Jr CW, Fregly BJ. Correlation between the knee adduction torque and medial contact force for a variety of gait patterns. Journal of Orthopaedic Research. 2007 Jun;25(6):789-97.

45. Andriacchi TP, Mündermann A, Smith RL, Alexander EJ, Dyrby CO, Koo $\mathrm{S}$. A framework for the in vivo pathomechanics of osteoarthritis at the knee. Annals of Biomedical Engineering. 2004 Mar;32(3):447-57.

46. Beck JL, Wildermuth BP. The female athlete's knee. Clinics in Sports Medicine. 1985 Apr 1;4(2):345-66.

47. Caraffa A, Cerulli G, Projetti M, Aisa G, Rizzo A. Prevention of anterior cruciate ligament injuries in soccer. Knee Surgery, Sports Traumatology, Arthroscopy. 1996 Mar 1;4(1):19-21.

48. Hewett TE, Riccobene JV, Lindenfeld TN. The effect of neuromuscular training on the incidence of knee injury in female athletes: A prospective study. Am J Sports Med. 1999;27:699-706.

49. Beard DJ, Dodd CA, Trundle HR, Simpson AH. Proprioception enhancement for anterior cruciate ligament deficiency. A prospective 
randomised trial of two physiotherapy regimes. The Journal of Bone and Joint Surgery. 1994 Jul;76(4):654-9.

50. Ageberg E, Zätterström R, Moritz U, Fridén T. Influence of supervised and nonsupervised training on postural control after an acute anterior cruciate ligament rupture: a three-year longitudinal prospective study. Journal of Orthopaedic \& Sports Physical Therapy. 2001 Nov;31(11):632-44.

51. Simic M, Hinman RS, Wrigley TV, Bennell KL, Hunt MA. Gait modification strategies for altering medial knee joint load: a systematic review. Arthritis Care \& Research. 2011 Mar;63(3):405-26.
52. Andriacchi TP, Mündermann A, Smith RL, Alexander EJ, Dyrby CO, Koo S. A framework for the in vivo pathomechanics of osteoarthritis at the knee. Annals of Biomedical Engineering. 2004 Mar;32(3):447-57.

53. Zhao D, Banks SA, Mitchell KH, D'Lima DD, Colwell Jr CW, Fregly BJ. Correlation between the knee adduction torque and medial contact force for a variety of gait patterns. Journal of Orthopaedic Research. 2007 Jun;25(6):789-97. 